\title{
基于低共熔溶剂聚合物电解质染料敏化太阳能电池研究
}

\author{
杨 英，张 政，高 菁，林泽华，严靖园，郭学益 \\ (中南大学冶金与环境学院, 长沙 410083)
}

摘 要: 以琼脂糖聚合物为基质, 1-甲基-2-吡咯烷酮(NMP)为溶剂，由尿素、氯化胆碱合成的低共熔溶剂(DES)作为 添加剂制备聚合物电解质用于制备准固态染料敏化太阳能电池(DSSC)。研究了尿素/氯化胆碱配比、低共熔溶剂添 加量对聚合物电解质电化学性能及其 DSSC 光电性能的影响。研究结果表明: 随着尿素/氯化胆碱配比增加, 准固 态电解质的导电性能增加，尿素、氯化胆碱的配比为 $2: 1$ 时可获得最佳电导率 $7.24 \mathrm{mS} / \mathrm{cm}$ 。对不同低共熔溶剂含量 电解质进行离子电导率测试研究发现: 添加量为 $20 \mathrm{wt} \%$ 时, 电解质获得最佳电导率 $6.21 \mathrm{mS} / \mathrm{cm}$ 。染料敏化太阳能电 池的光电效率随低共熔溶剂含量的增加先增加后降低, 低共熔溶剂添加量为 $20 \mathrm{wt} \%$ 时, 获得最佳光电效率 $\eta=3.18 \%$, 短路电流密度 $J_{\mathrm{sc}}=10.28 \mathrm{~mA} / \mathrm{cm}^{2}$, 开路电压 $V_{\mathrm{oc}}=0.59 \mathrm{~V}$, 填充因子 $F F=0.51$ 。

关 键 词: 染料敏化太阳能电池; 低共熔溶剂; 尿素; 氯化胆碱; 聚合物电解质

中图分类号: TM914 文献标识码: A

\section{Deep Eutectic Solvent Based Polymer Electrolyte for Dye-sensitized Solar Cells}

\author{
YANG Ying, ZHANG Zheng, GAO Jing, LIN Ze-Hua, YAN Jing-Yuan, GUO Xue-Yi \\ (School of Metallurgy and Environment, Central South University, Changsha 410083, China)
}

\begin{abstract}
A polymer electrolyte using agarose as polymer matrix, NMP as solvent and deep eutectic solvent (DES) as modifier was investigated and employed in quasi-solid-state dye-sensitized solar cells (DSSC) of which the DES was composed by urea and choline chloride. The ionic conductivity of the polymer electrolytes with different urea /choline chloride ratio was studied. It was found that the maximum ionic conductivity of the polymer electrolyte was obtained at urea/choline chloride ratio of 2:1. Under the optimal urea /choline chloride ratio condition, electrochemical properties of the polymer electrolytes and the photovoltaic properties were systematically characterized by photovoltaic tests and electrochemical impedance spectra (EIS). The results showed that both ionic conductivity of electrolyte and photovoltaic performances of the DSSC was optimized with DES content of $20 \mathrm{wt} \%$, where the device photovoltaic parameters were as follows, $V_{\mathrm{oc}}$ at $0.59 \mathrm{~V}, J_{\mathrm{sc}}$ at $10.28 \mathrm{~mA} / \mathrm{cm}^{2}, F F$ at 0.51 , and the cell efficiency at $3.18 \%$.
\end{abstract}

Key words: dye sensitized solar cell; deep eutectic solvent; urea; choline chloride; polymer electrolyte

自 Michael Grätze 发明染料敏化太阳能电池 (Dye-sensitized solar cells, DSSC)并在 1991 年取得 突破进展以来, DSSC 以其低廉的制作成本(仅为硅
太阳能电池的 1/5 1/10)、丰富的原材料和易于工业 化的生产技术得到了广泛关注 ${ }^{[1]}$ 。

在 DSSC 中, 电解质的主要作用是输送电荷。

收稿日期: 2016-03-28; 收到修改稿日期：2016-06-02

基金项目: 中南大学创新驱动计划项目(2016CX022); 中南大学教师基金(905010104); 留学回国基金以及中南大学大学生 创新创业项目(201510533205, CX2015237)

Third Innovation Driven Project of Central South University (2016CX022); Teacher Research Fund of Central South University (905010104); Scientific Research Foundation for the Returned overseas Chinese Scholar, State Education Ministry and the Projects of Innovation for Graduate Student in CSU(201510533205, CX2015237)

作者简介: 杨 英(1980-), 女, 副教授. E-mail: muyicaoyang@csu.edu.cn

通讯作者: 郭学益, 教授. E-mail: xyguo@csu.edu.cn 
通过研究电解质中各个组分对 Pt 对电极/电解质的 界面反应的影响发现, 电解质中氧化还原电对的传 输越快, 对电极/电解质界面的电子交换速度越快, 越有利于 DSSC 光电性能的提高 ${ }^{[2-3]}$ 。目前, 由液态 电解质所制备的 DSSC 光电转换效率可达到 13\% ${ }^{[4-5]}$, 但是液态电解质具有封装难、易泄露、光热不稳定 等缺点，限制了其发展与商业化 ${ }^{[6-7]}$ 。引入基于 $\mathrm{p}$ 型 半导体材料, 空穴传输材料的全固态电解质代替液 态电解质是解决上述问题的一种途径, 但是全固态 电解质存在电导率低, 与光阳极多孔膜界面浸润性 差等问题 ${ }^{[1]}$ 。准固态电解质, 如聚合物电解质, 具有 较高的电导率和光电转换效率, 可以有效促进电解 质的渗透, 延长器件使用寿命, 被广泛应用于染料 敏化太阳能电池中。

由于离子液体具有较高的导电性、热稳定性及 稳定的电化学窗口, 因此, 在聚合物体系引入离子是 一种可以显著提高电解质导电性的有效方法 ${ }^{[8-9]}$ 。但是 诸如 1-丙基-3-甲基咪唑碘(HMII)、 $\operatorname{EMImN}(\mathrm{CN})_{2}$ 、三 烷基锍类、咪唑类、季胺碘盐类 ${ }^{[10-16]}$ 离子液体虽然 具有较高的电导率, 但是价格昂贵、毒性较大。 Abbott 等 ${ }^{[17-19]}$ 发现的一种由季铵盐和酰胺化合物组 成的低共熔溶剂离子液体, 具有如下优点: (1)电化 学窗口宽, 制备简单, 价格低廉, 无毒, 可由尿素 与氯化胆碱在室温下合成; (2)导电性良好, $\mathrm{I}_{3}{ }^{-}$的扩 散系数 ${ }^{[20]}$ 高达 $8.7 \times 10^{-7} \mathrm{~cm}^{2} / \mathrm{s}$, 远高于其他离子液态; (3)低共熔溶剂分解产生的离子将与聚合物之间连 接的差基相互作用, 加强聚合物的非晶性 ${ }^{[21]}$, 提高 电解质中离子迁移率。因此本工作选取低共熔溶剂 作为琼脂糖基准固态聚合物电解质的添加剂, 而该 类低共溶剂在准固态染料敏化太阳能电池中的应用 尚未见报道。本工作选取该尿素/氯化胆碱低共熔溶 剂作为琼脂糖基准固态聚合物电解质的添加剂, 系 统研究了尿素/氯化胆碱配比以及尿素/氯化胆碱低 共熔溶剂含量对聚合物电解质电化学性能以及相应 染料敏化太阳能电池的光电性能的影响。

\section{1 实验方法}

\section{1 试剂与仪器}

$\mathrm{TiO}_{2}(\mathrm{P} 25,20 \sim 30 \mathrm{~nm}$, Degussa AG), 导电玻璃 (30 $\Omega \cdot \square^{-1}, F T O$, 秦皇岛耀华有限公司); 染料(N719, 苏州中晟化工有限公司); 尿素(Urea, 98\%, SIGMAALORICH); 氯化胆碱(Choline chloride, 98\%, 北京 百灵威科技有限公司); 琼脂糖(AG，分子量：3000 5000, 生化试剂); 1-甲基-2-吡咯烷酮(NMP, 化学纯,
上海国药集团化学试剂有限公司); 碘化锂(LiI, 99\%, Acros Organics); 碘 $\left(\mathrm{I}_{2}\right.$, 分析纯, 湖南汇虹试剂有限 公司); 曲拉通(TritonX-100, 化学纯, 汕头市西陇化 工厂); 乙酰丙酩(分析纯, 天津市福晨化学试剂厂)。

\section{2 低共熔溶剂电解质的制备}

低共熔溶剂的制备: 称取一定质量的氯化胆碱 加入 $10 \mathrm{~g}$ 尿素中, 使尿素/氯化胆碱摩尔比分别为 $4: 1 、 3: 1 、 2: 1 、 1: 1 、 1: 1.5 、 1: 2 、 1: 3$, 倒入 $60 \mathrm{~mL}$ 的棕色瓶。将棕色瓶放置在水浴搅拌器上 $80^{\circ} \mathrm{C}$ 加热 搅拌, 直至形成无色透明的液体, 真空干燥 $12 \mathrm{~h}$, 得到低共熔溶剂(图 1(a))。

不同尿素/氯化胆碱配比的低共熔溶剂聚合物 电解质制备: 将 $0.4062 \mathrm{~g}$ 琼脂糖加入 $20 \mathrm{~g}$ 1-甲基-2吡咯烷酮(NMP)中, 在 $80^{\circ} \mathrm{C}$ 恒温水浴下搅拌 $4 \mathrm{~h}$, 之 后加入 $0.1361 \mathrm{~g} \mathrm{LiI}$ 和 $0.2582 \mathrm{~g} \mathrm{I}_{2}$, 常温下磁力摚拌 $4 \mathrm{~h}$ 。向以上聚合物电解质溶液体系中分别加入 $20 \mathrm{wt} \%$ 不同尿素/氯化胆碱配比的低共熔溶剂(尿素/ 氯化胆碱摩尔比分别为 $4: 1 、 3: 1 、 2: 1 、 1: 1 、 1: 1.5$ 、 $1: 2 、 1: 3)$, 制备得到不同尿素/氯化胆碱配比的低共 熔溶剂聚合物电解质(图 1(b))。

不同含量低共熔溶剂改性电解质溶液的制备: 将 $0.4062 \mathrm{~g}$ 琼脂糖加入 $20 \mathrm{~g}$ 1-甲基-2-吡咯烷酮(NMP) 中, 在 $80^{\circ} \mathrm{C}$ 恒温水浴下搅拌 $4 \mathrm{~h}$, 加入 $0.1361 \mathrm{~g} \mathrm{LiI}$ 和 $0.2582 \mathrm{~g} \mathrm{I}_{2}$ 到以上体系, 在常温下磁力搅拌 $4 \mathrm{~h}$ 。 向以上溶液体系中分别加入尿素/氯化胆碱摩尔比 为 $2: 1$ 低共熔溶剂，含量分别控制为 $0 、 10 \mathrm{wt} \%$ 、 $20 \mathrm{wt} \% 、 40 \mathrm{wt} \%$ 、60wt \%、80wt\%。

\section{3 准固态染料敏化太阳能电池的组装}

$\mathrm{TiO}_{2}$ 浆料的制备: 向棕色瓶中加入 $5 \mathrm{~g} \mathrm{P} 25$ 纳 米二氧化钛粉末, 并向其中加入 $0.4 \mathrm{~mL}$ 曲拉通 X-100、0.8 mL 乙酰丙酮和 $10 \mathrm{~mL}$ 无水乙醇。将棕 色瓶密封, 在室温下磁力搅拌 $24 \mathrm{~h}$ 。然后在向其中, 加入无水乙醇 $45.5 \mathrm{~mL}$, 再次放入集热式恒稳加热 磁力摚拌器中, 在室温下磁力搅拌 $24 \mathrm{~h}$ 得到呈乳白 色的前驱体浆料。

光阳极的制备: 纳米晶 $\mathrm{TiO}_{2}$ 光阳极的制备采用 的是 Doctor-Blading 法, 涂膜形成厚度约为 $10 \mu \mathrm{m}$ 厚的 $\mathrm{TiO}_{2}$ 膜。将其放入 $85^{\circ} \mathrm{C}$ 烘干箱中迅速烘干 $10 \mathrm{~s}$, 取出再次涂敷, 重复 3 次。将烘干后的 $\mathrm{TiO}_{2}$ 放置于 箱式电阻炉, 在 $450^{\circ} \mathrm{C}$ 下高温烧结 $30 \mathrm{~min}$, 冷却至室 温。最后将热处理后的光阳极用无水乙醇冲洗干净 后放入 $100^{\circ} \mathrm{C}$ 干燥箱中烘干 $30 \mathrm{~min}$, 完全去除水分。

准固态染料敏化太阳能电池的组装: 采用刮涂 法制备的 $\mathrm{TiO}_{2}$ 光阳极浸入联吡啶钉染料 $\mathrm{N} 719\left[\mathrm{RuL}_{2}(\mathrm{NCS})_{2}: 2 \mathrm{TBA}\right]$ 的无水乙醇溶液中室温避 
光浸泡 $24 \mathrm{~h}$ 后取出, 得到敏化完成的光阳极。向光 阳极滴加低共熔溶剂聚合物电解质, 放入烘箱烘至 胶状, 盖上铂片, 将电池用夹子封装, 放入真空干燥 箱 $80^{\circ} \mathrm{C}$ 干燥 $2.5 \mathrm{~h}$, 得到染料敏化太阳能电池。

\section{4 表征方法}

紫外可见光谱测试: 用 UV-1800 紫外-可见分 光光度计(岛津公司)在室温下完成含低共熔溶剂聚 合物电解质的紫外可见吸收光谱的测试, 扫描速度 设定为中速，波长选取为 200 600 nm。

离子电导率测试: 用电化学工作站 CHI604D (上海辰华仪器有限公司)上在室温下完成含低共熔 溶剂聚合物电解质的离子电导率的测试, 频率范围 为 $10 \mathrm{~Hz} \sim 1 \mathrm{MHz}$, 扰动电压为 $10 \mathrm{mV}$ 。离子电导率 可以通过公式(1)进行计算

$$
\sigma=L / A R_{\mathrm{b}}
$$

其中, $L$ 是低共熔溶剂电解质膜的厚度, $A$ 是电解质 与铂片的接触面积, $R_{\mathrm{b}}$ 是电解质的体电阻。

表面形貌测试: 采用 JSM-6360LV 型扫描电子 显微镜观察样品表面形貌。制样过程如下: 在载玻 片上用透明胶带贴出 $1.5 \mathrm{~cm} \times 1.5 \mathrm{~cm}$ 区域, 控制电解 质的体积在 $200 \mu \mathrm{L}$ 左右, 将电解质滴加在区域中, 并放入烘箱 $75^{\circ} \mathrm{C}$ 下烘烤 $2.5 \mathrm{~h}$ 。所制备电解质薄膜用 于 SEM 检测。

DSSC 的光电性能测试: 利用 CH1604D 电化 学工作站检测电池的光电效率, 采用 Xe 灯作为模 拟光源, 光强通过标准二极管 (Si 1708)测定。光强 $100 \mathrm{~mW} / \mathrm{cm}^{2}$, 采光面积控制为 $0.25 \mathrm{~cm}^{2}$ 。

DSSC 的交流阻抗测试: 在电化学工作站 CH1604D 上测试电池的电化学交流阻抗(EIS), 频 率范围是 $0.05 \sim 10^{5} \mathrm{~Hz}$, 所加的扰动电压是 $10 \mathrm{mV}$ 。

DSSC 的稳定性测试: 将电池置于 $30^{\circ} \mathrm{C}$ 恒温箱, 利用 CH1604D 电化学工作站每隔 $15 \mathrm{~h}$ 对电池进行 光电性能检测, 模拟光源的光强通过标准二极管 $(\mathrm{Si}$ 1708)测定。控制光强 $100 \mathrm{~mW} / \mathrm{cm}^{2}$, 采光面积控制 为 $0.25 \mathrm{~cm}^{2}$ 。

\section{2 结果与讨论}

\section{1 不同尿素/氯化胆碱配比的低共熔溶剂对 电解质的影响}

\subsection{1 紫外-可见光谱分析}

图 2 所示为不同尿素/氯化胆碱配比的低共熔溶 剂改性电解质的紫外可见光吸收光谱图。其中, 波 长为 $300 \mathrm{~nm}$ 和 $375 \mathrm{~nm}$ 处的峰位对应 $\mathrm{I}_{3}{ }^{-}$的吸收峰位 ${ }^{[22]}$, 峰强度越高, 代表 $\mathrm{I}_{3}{ }^{-}$的浓度越大。如图 2 所示, 吸
收峰强度随着氯化胆碱配比的增加而增强, 在尿素/ 氯化胆碱摩尔比为 2:1 时, 吸收峰强度达到最大值, 说明 $\mathrm{I}_{3}{ }^{-1}$ 离子浓度达到最大值。

分析低共熔溶剂的结构可知, 低共熔溶剂是 由体积较大且不对称的有机阳离子和阴离子所组 成。Abbott 等 ${ }^{[23]}$ 提出低共熔溶剂的形成过程如式(2) 所示:

阳离子+阴离子+氢键供体↔阳离子+配位阴离子 (2)

应用于本实验所用尿素/氯化胆碱体系，反应式 可表示为:

$$
\begin{aligned}
& {\left[\mathrm{HOC}_{2} \mathrm{H}_{4} \mathrm{~N}\left(\mathrm{CH}_{3}\right)_{3}\right]^{+}+[\mathrm{Cl}]^{-}+n \mathrm{NH}_{2} \mathrm{CONH}_{2} \leftrightarrow} \\
& {\left[\mathrm{HOC}_{2} \mathrm{H}_{4} \mathrm{~N}\left(\mathrm{CH}_{3}\right)_{3}\right]^{+}+\left(\mathrm{NH}_{2} \mathrm{CONH}_{2}\right)_{n}[\mathrm{Cl}]^{-}}
\end{aligned}
$$

当尿素/氯化胆碱摩尔比为 $2: 1$ 时, 低共熔溶剂 的结构如图 3 所示。孙辉等 ${ }^{[24]}$ 通过分子动力学模拟 考察了不同尿素含量的低共熔溶剂的结构性质，提 出并解释了尿素/氯化胆碱(2:1)时, 低共熔溶剂低熔 点、高电导率等特殊化学性质的形成机制。进一步 研究表明，此时低共熔溶剂的物理化学性质适合于

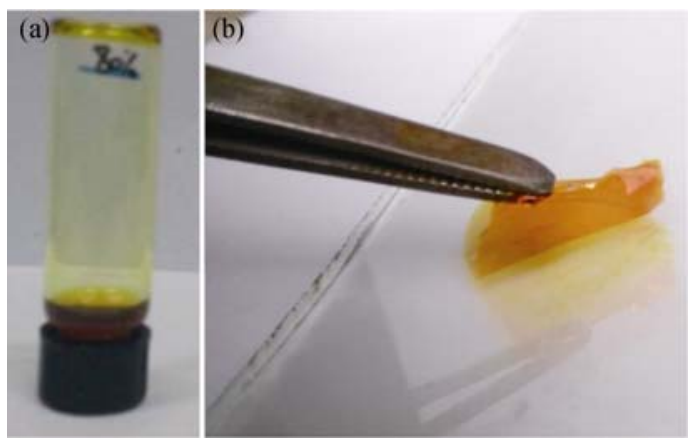

图 1 (a)低共熔溶剂聚合物电解质溶液和(b)低共熔溶剂聚合 物电解质烘干后实物图

Fig. 1 Pictures of (a) DES based polymer electrolyte solution and (b) DES based polymer electrolyte film after drying

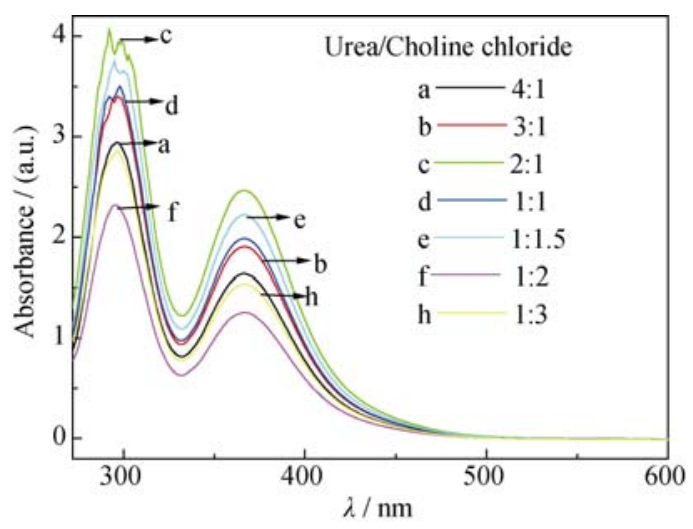

图 2 不同尿素/氯化胆碱配比低共熔熔剂改性电解质的紫外 吸收光谱图

Fig. 2 UV-Vis spectra of electrolytes modified by DES with different urea/choline chloride ratios 


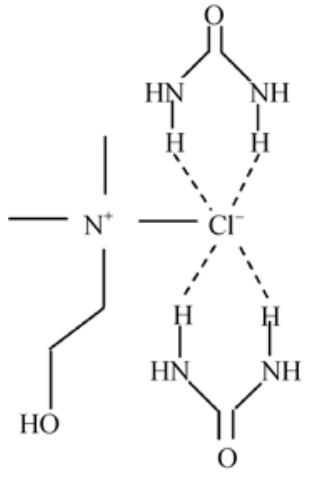

图 3 尿素/氯化胆碱摩尔比为 2:1 的低共熔熔剂结构示意图 Fig. 3 Structural representation of the DES with urea/ choline chloride of 2: 1

化电化学、催化、有机合成、溶解与萃取以及材料 学等诸多领域的应用 ${ }^{[25-26]}$ 。

加入低共熔溶剂, 高电负性 $\left(\mathrm{NH}_{2} \mathrm{CONH}_{2}\right)_{2}[\mathrm{Cl}]^{-}$ 会部分离解产生自由 $\mathrm{Cl}^{-}$及氢键给体 $\left(\mathrm{NH}_{2} \mathrm{CONH}_{2}\right)$, 这些氢键给体 $\left(\mathrm{NH}_{2} \mathrm{CONH}_{2}\right)$ 会与聚合物内部的羟基 作用, 加强聚合物结构的非晶性 ${ }^{[21]}$, 这将有利于电 解质中离子的迁移。另一方面, 低共熔溶剂作为一 种离子液体, 具有较高的离子场强度, 由于动力学 盐效应 ${ }^{[27]}$, 优化了电解质中 $\mathrm{I}_{2}$ 和 $\mathrm{I}$ 运动的动力学条 件, 从而提高其接触机率, 有利于 $\mathrm{I}_{3}{ }^{-}$的形成。但当 尿素/氯化胆碱摩尔比高于 $2: 1$ 时, 低共熔溶剂的结 构发生改变, 弱化了其电化学性能, 不利于溶剂中 的离子迁移 ${ }^{[24]}$ 。同时, 配比改变后, 低共熔溶剂中 含有过多的氢键给体 $\left(\mathrm{NH}_{2} \mathrm{CONH}_{2}\right)$ 和自由 $\mathrm{Cl}^{-}$, 这些 过剩的自由 $\mathrm{Cl}^{-}$或氢键给体 $\left(\mathrm{NH}_{2} \mathrm{CONH}_{2}\right)$ 与 $\mathrm{I}_{3}{ }^{-}$和 $\mathrm{Li}^{+}$ 相互影响, 降低了电解质中自由离子数目, 反而使

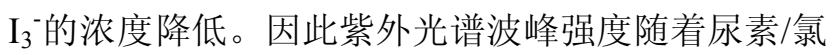
化胆碱配比的增加呈现先升高后降低的变化趋势, 在尿素/氯化胆碱摩尔比为 $2: 1$ 时吸光度达到最高值。

\subsection{2 离子电导率分析}

图 4 为不同尿素/氯化胆碱配比的低共熔溶剂改 性电解质膜的离子电导率。由图 4 可以看出, 低共 熔溶剂改性的电解质的离子电导率随着尿素/氯化 胆碱配比的升高, 先增加后降低, 在尿素/氯化胆碱 为 $2: 1$ 处获得最大离子电导率 $(7.24 \mathrm{mS} / \mathrm{cm})$ 。

由前述分析可知, 加入低共熔溶剂, $\left(\mathrm{NH}_{2} \mathrm{CONH}_{2}\right)_{2}$ $[\mathrm{Cl}]^{-1}$ 离解后生成的自由 $\mathrm{Cl}^{-}$, 会使电解质中自由离子 增加, 加快带电粒子的传输, 提升低共熔溶剂改性 电解质的离子电导率与 $\mathrm{I}_{3}$ 浓度。另一方面, 低共熔溶 剂将提高电解质的非晶程度, 降低电解质粘度 ${ }^{[21]}$ 。根 据 Nernst-Einstein 方程, 粘度越低, 离子电导率越 高。但当尿素/氯化胆碱摩尔比大于 $2: 1$ 时, 低共熔

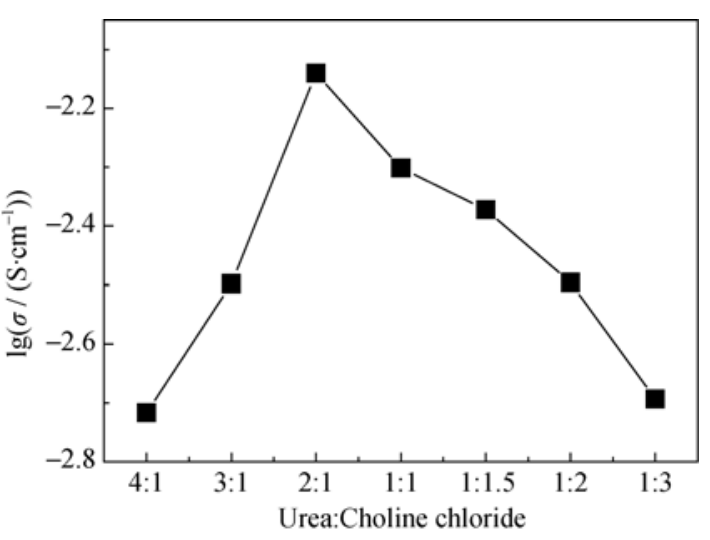

图 4 不同尿素/氯化胆碱配比的低共熔溶剂的电解质的离子 电导率图

Fig. 4 Ionic conductivity of electrolytes with DES of different urea/choline chloride ratio

溶剂的结构改变, 不利于离子的自由移动 ${ }^{[22]}$ 。

\section{2 低共熔溶剂含量对电解质的影响}

\subsection{1 表面形貌分析}

图 5 是不同含量低共熔溶剂改性的聚合物电解 质的 SEM 照片, 由图中可以看出，当加入低共熔溶 剂小于 $20 \mathrm{wt} \%$ 时，电解质表面较为平滑，这是由于低 共熔溶剂分解产生的氢键给体 $\left(\mathrm{NH}_{2} \mathrm{CONH}_{2}\right)$ 会与聚合 物内部的羟基作用, 加强聚合物结构的非晶性 ${ }^{[21]}$ 。当 低共熔溶剂含量为 $40 \mathrm{wt} \%$ 和 $60 \mathrm{wt} \%$ 时，电解质中出 现少量皱褶, 这是由于过量低共熔溶剂颗粒所形成 的中性粒子聚集体所造成的 ${ }^{[27]}$ 。当低共熔溶剂含量 达到 $80 \mathrm{wt} \%$ 时，电解质表面出现大量皱褶，这是由 于过量的低共熔溶剂将产生大量的氢键给体 $\left(\mathrm{NH}_{2} \mathrm{CONH}_{2}\right)$, 破坏了琼脂糖之间的连接, 成膜性 能变差, 影响电解质的表面形貌。

\subsection{2 紫外可见光谱分析}

图 6 所示为不同含量低共熔溶剂(尿素/氯化胆 碱 $=2: 1$ )改性聚合物电解质的紫外可见光吸收光谱图。 $300 \mathrm{~nm}$ 和 $375 \mathrm{~nm}$ 处的峰位对应 $\mathrm{I}_{3}{ }^{-}$的吸收峰位 ${ }^{[22]}$, 吸收峰强度随着低共熔溶剂(DES)含量增加先升高 后降低。在低共熔溶剂含量为 $20 \mathrm{wt} \%$ 时, 吸收峰强 度达到最大值。

低含量低共熔溶剂的加入促进了 $\mathrm{I}_{3}{ }^{-}$的生成, 有 利于电解质中离子电导率的增加。加入过量低共熔 溶剂后 $(>20 \mathrm{wt} \%)$, 大量 $\left(\mathrm{NH}_{2} \mathrm{CONH}_{2}\right)_{2}[\mathrm{Cl}]^{-}$发生离解, 自由 $\mathrm{Cl}^{-}$与氢键给体 $\left(\mathrm{NH}_{2} \mathrm{CONH}_{2}\right)$ 将影响 $\mathrm{I}_{3}$ 的形成, 降低 $\mathrm{I}_{3}$-浓度。因此紫外光谱波峰强度随着低共熔溶 剂含量的增加先增加后降低。

\subsection{3 离子电导率分析}

图 7 为不同含量低共熔溶剂改性电解质膜的离 

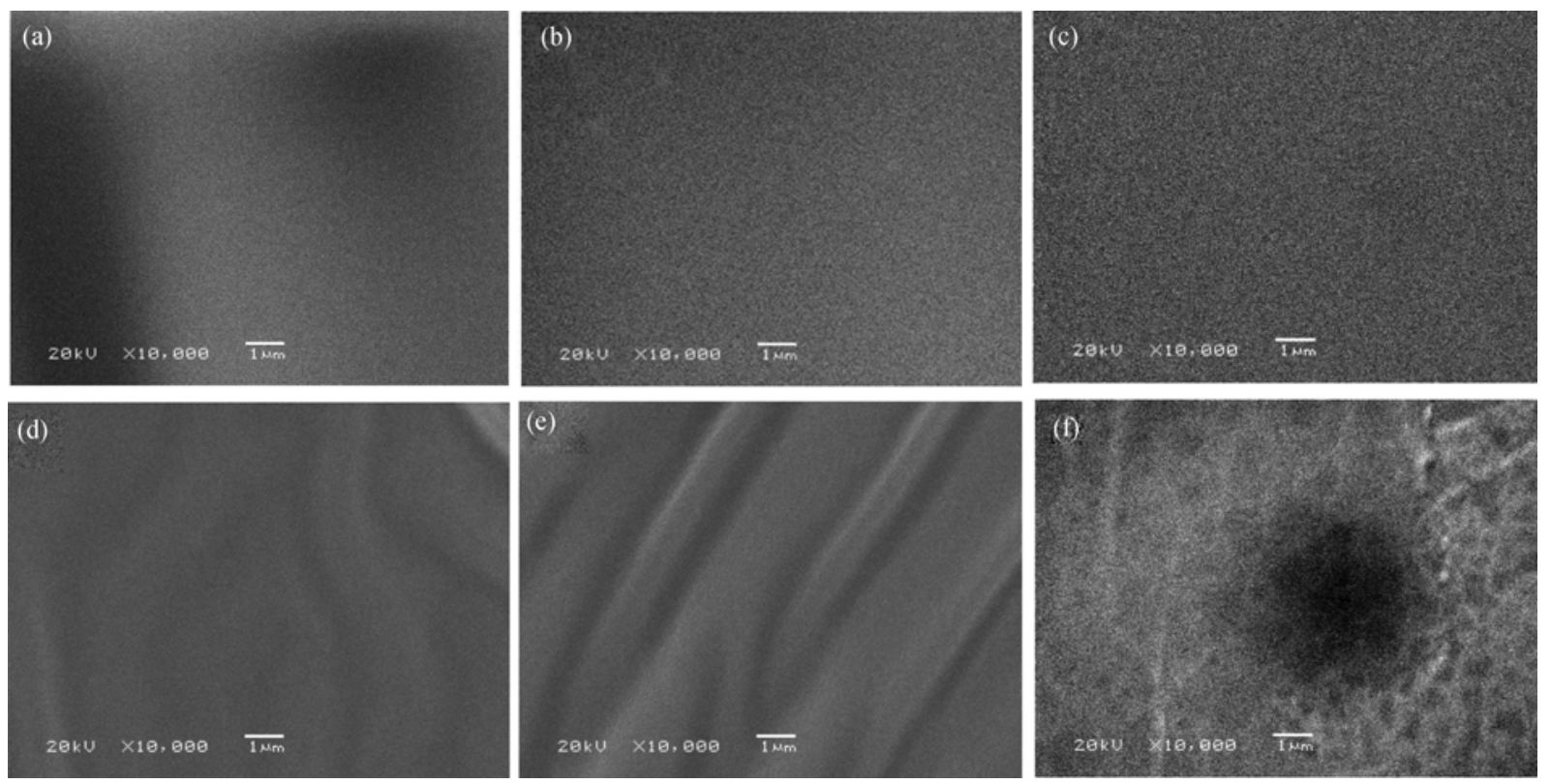

图 5 不同含量低共熔溶剂改性的聚合物电解质的 SEM 照片

Fig. 5 SEM images of polymer electrolyte with different contents of DES

(a) 0 ; (b) $10 \mathrm{wt} \%$; (c) $20 \mathrm{wt} \%$; (d) $40 \mathrm{wt} \%$; (e) $60 \mathrm{wt} \%$; (f) $80 \mathrm{wt} \%$

子电导率。由图可知, 低共熔溶剂改性电解质的离 子电导率随着低共熔溶剂含量的增加呈现先增加后 降低的变化趋势，20wt\% 低共熔溶剂改性样品达到 最大值 $6.21 \mathrm{mS} / \mathrm{cm}$ 。

低含量低共熔溶剂(DES)的加入, 有利于电解 质离子电导率的提高。但过量低共熔溶剂颗粒将形 成大量中性粒子聚集体 ${ }^{[27]}$, 降低聚合物电解质的界 面能, 从而阻断现有的导电通路 ${ }^{[28-29]}$ 。另一方面, 过 量低共熔溶剂中自由 $\mathrm{Cl}^{-}$会与 $\mathrm{I}_{3}{ }^{-}$和 $\mathrm{Li}^{+}$相互作用, 降 低电解质中的自由离子浓度。因此离子电导率随着 低共熔溶剂的增加, 先增加而后降低。

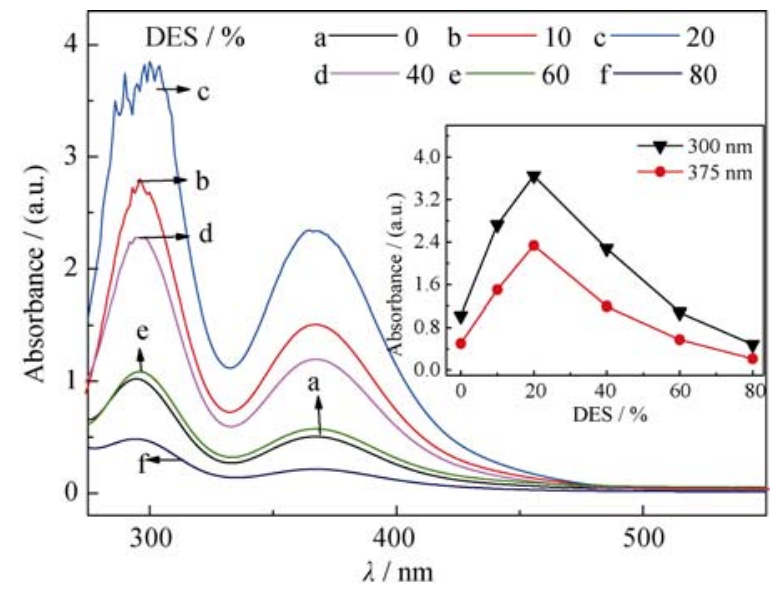

图 6 不同含量低共熔溶剂改性电解质的紫外吸收光谱图

Fig. 6 UV-Vis spectra of electrolytes modified with different contents of DES

\section{3 不同含量低共熔溶剂改性聚合物电解质 DSSC 性能分析}

\subsection{1 光电性能分析}

图 8 是不同含量低共熔溶剂改性电解质染料敏 化太阳能电池在光强为 $100 \mathrm{~mW} / \mathrm{cm}^{2}$ 时的 $J-V$ 曲线。 表 1 是对应染料敏化太阳能电池的光电性能各项参 数。从图 8 和表 1 可以看出, 不含低共熔溶剂时, 短 路电流密度 $J_{\mathrm{sc}}=8.36 \mathrm{~mA} / \mathrm{cm}^{2}$; 当加入 $10 \mathrm{wt} \%$ 和 $20 \mathrm{wt} \%$ 的低共熔溶剂(DES)时, 短路电流密度 $J_{\mathrm{sc}}$ 迅 速升高至 $10.32 \mathrm{~mA} / \mathrm{cm}^{2}$ 和 $10.28 \mathrm{~mA} / \mathrm{cm}^{2}$, 该现象表 明加入低共熔溶剂可以大幅度提高电池的短路电流 密度。继续增加低共熔溶剂含量至 $80 \mathrm{wt} \%$, 短路电 流密度 $J_{\mathrm{sc}}$ 下降到 $2.40 \mathrm{~mA} / \mathrm{cm}^{2}$, 这与图 6 与图 7 的

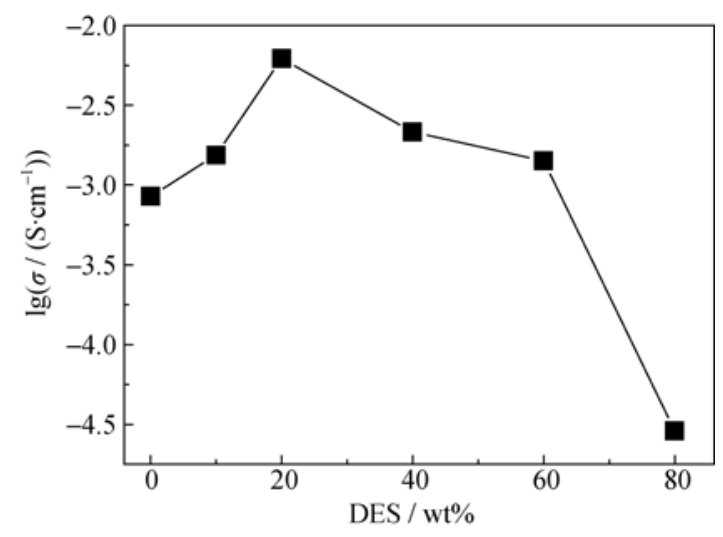

图 7 不同含量低共熔溶剂改性电解质的离子电导率图

Fig. 7 Ionic conductivity of electrolytes modified with different contents of DES 
变化规律基本一致。低共熔溶剂的加入, 导致离子 电导率升高, 降低电解质的串联电阻, 增加 $\mathrm{I}_{3}{ }^{-}$的浓 度及扩散速度, 从而加速了界面之间的电子转移, 提高了短路电流密度。当低共熔溶剂含量过高时, 电导率与 $\mathrm{I}_{3}$ 浓度的下降导致短路电流密度的降低。

对于光电效率的分析也可以得到类似的结论, 当低 共熔溶剂含量为 $20 \mathrm{wt} \%$ 时, 所制备的染料敏化电池 的光电效率达到最大值 $3.18 \%$, 与短路电流密度的 变化一致。

我们知道导带中电子浓度 $Q_{\mathrm{cb}}$ 决定着导带边 $E_{\mathrm{cb}}$ 与费米能级 $E_{\mathrm{f}}$ 之差, 即 $E\left(Q_{\mathrm{cb}}\right)=E_{\mathrm{cb}}-E_{\mathrm{f}}^{[30-31]}$, 而开路 电压 $V_{\mathrm{oc}}$ 等于费米能级 $E_{\mathrm{f}}$ 与氧化还原电对电位差 $E_{\text {redox }}$ 之差, 在 $E_{\text {redox }}$ 不变的条件下, 导带中电子浓 度的增加将使导带边 $E_{\mathrm{cb}}$ 与费米能级 $E_{\mathrm{f}}$ 上移, 从而 使开路电压 $V_{\mathrm{oc}}$ 增加。由表 1 可知, 随着低共熔溶剂 由 $0 \mathrm{wt} \%$ 增加到 $20 \mathrm{wt} \%$, 电解质中 $\mathrm{I}_{3}{ }^{-}$的离子浓度升 高, 加快了染料分子的氧化还原速度和电子的传输 速度, 提高了二氧化钛光阳极中电子浓度 ${ }^{[1]}$, 从而 导致 $V_{\mathrm{oc}}$ 由 $0.44 \mathrm{~V}$ 增加至 $0.59 \mathrm{~V}$ 。继续增加低共熔 溶剂含量, $V_{\mathrm{oc}}$ 呈现先降后升的变化趋势, 最终在 $80 \mathrm{wt} \%$ 处得到最大值 $0.71 \mathrm{~V}$ 。这是由于在较高低共 熔溶剂含量下, $\mathrm{I}_{3}{ }^{-}$的离子浓度降低, 不利于 $V_{\mathrm{oc}}$ 的增 大, 但过量的 $\left(\mathrm{NH}_{2} \mathrm{CONH}_{2}\right)_{2}[\mathrm{Cl}]^{-}$发生离解产生自由 $\mathrm{Cl}^{-}$与氢键给体 $\left(\mathrm{NH}_{2} \mathrm{CONH}_{2}\right)$, 破坏染料分子之间氢 键的交互作用，减少了染料之间的团聚，增加二氧 化钛光阳极中电子的浓度, 从而使 $V_{\mathrm{oc}}$ 增加 ${ }^{[1]}$ 。

综上所述: 在 $20 \mathrm{wt} \%$ 低共熔溶剂含量下, 得到 最佳光电性能, 此时, 开路电压 $V_{\mathrm{oc}}=0.53 \mathrm{~V}$, 短路电 流密度 $J_{\mathrm{sc}}=10.28 \mathrm{~mA} / \mathrm{cm}^{2}$, 光电效率 $\eta=3.18 \%$ 。而未 加入低共熔溶剂的 DSSC, 开路电压 $V_{\mathrm{oc}}=0.36 \mathrm{~V}$, 短 路电流密度 $J_{\mathrm{sc}}=8.36 \mathrm{~mA} / \mathrm{cm}^{2}$, 光电效率 $\eta=1.24 \%$ 。

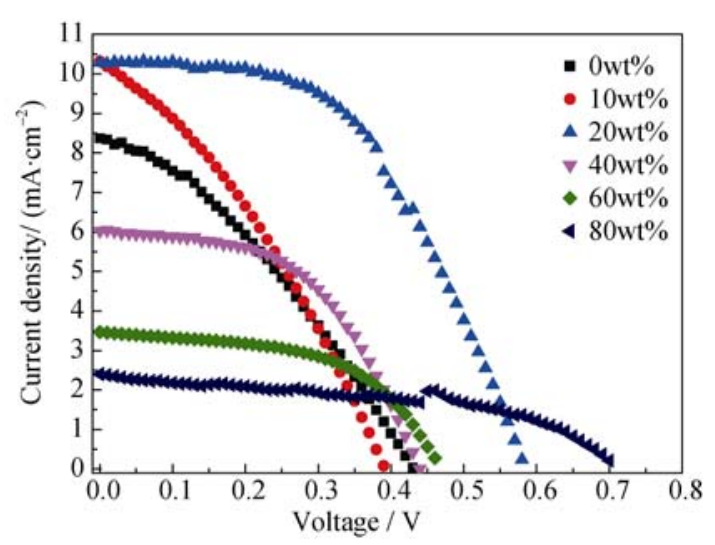

图 8 不同含量低共熔溶剂改性电解质染料敏化太阳能电池 的 $J-V$ 曲线图

Fig. $8 \quad J-V$ characteristics of the DSSCs fabricated using electrolytes modified with different contents of DES
表 1 不同含量低共熔溶剂电解质电池光电性能关键参数

Table 1 Performance parameters of the DSSCs fabricated using electrolytes modified with different contents of DES

\begin{tabular}{ccccc}
\hline$\omega / \mathrm{wt} \%$ & $J_{\mathrm{sc}} /\left(\mathrm{mA} \cdot \mathrm{cm}^{-2}\right)$ & $V_{\text {oc }} / \mathrm{V}$ & $F F$ & $\eta / \%$ \\
\hline 0 & 8.36 & 0.44 & 0.33 & $1.24 \%$ \\
10 & 10.32 & 0.40 & 0.33 & $1.40 \%$ \\
20 & 10.28 & 0.59 & 0.51 & $3.18 \%$ \\
40 & 6.04 & 0.45 & 0.50 & $1.41 \%$ \\
60 & 3.46 & 0.47 & 0.54 & $0.91 \%$ \\
80 & 2.40 & 0.71 & 0.54 & $0.93 \%$ \\
\hline
\end{tabular}

\subsection{2 交流阻抗分析}

图 9 为不同含量低共熔溶剂改性聚合物电解质 DSSC 的 Bode 图, 图中位于 1 1000 $\mathrm{Hz}$ 的中频部分 反映的是 $\mathrm{TiO}_{2}$ /电解质界面的电化学性能 ${ }^{[22-34]}$ 。由图 9 可以看出, 随着低共熔溶剂含量的增加, 其特征峰 峰值从 $100 \mathrm{~Hz}(0 \mathrm{wt} \%)$ 降低到 $6.309 \mathrm{~Hz}(20 \mathrm{wt} \%)$, 之后 又升高至 $50.1 \mathrm{~Hz}(40 \mathrm{wt} \%)$ 。继续增加低共熔溶剂含量, 其特征峰峰值将降低至 $5.01 \mathrm{~Hz}(80 \mathrm{wt} \%)$ 。

根据 EIS 理论, 在 Bode 图的中频区特征峰峰值 处频率 $(\omega)$ 与电荷电子寿命 $(\tau)$ 之间的关系可由公式 (4)表示 ${ }^{[35]}$

$$
\omega=\tau^{-1}
$$

由公式(4)可得光阳极中电荷的电子寿命与低 共熔溶剂浓度之间的关系图, 如图 10 所示。由图 10 可得, $\mathrm{TiO}_{2}$ 多孔薄膜中电荷电子寿命先增加后降低 而后继续增加，最终在 $80 \mathrm{wt} \%$ 处电子寿命达到最 高。这是由于加入低含量低共熔溶剂, 加强了聚合 物电解质的非晶性 ${ }^{[21]}$, 提高了电解质的电导率, 促 进了电子在电极与电解质界面间的转移, 从而使电 子寿命增加。但加入过量低共熔溶剂后，低共熔溶 剂颗粒将形成大量中性粒子聚集体 ${ }^{[27]}$ ，降低聚合物

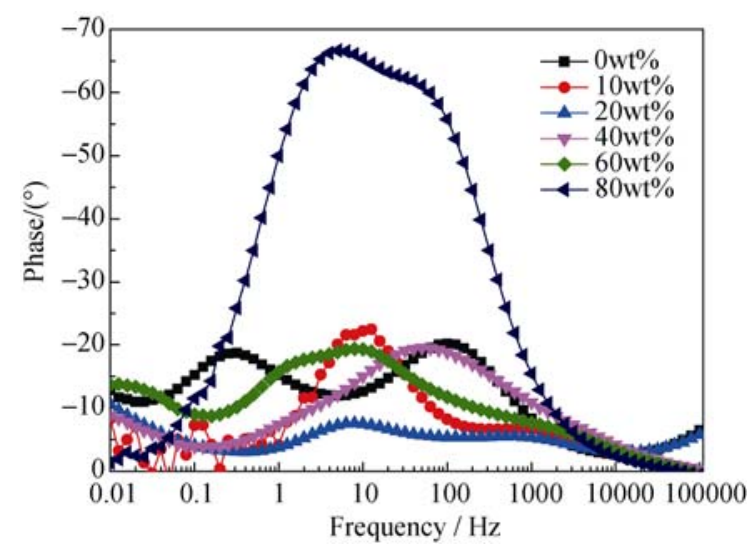

图 9 不同含量低共熔溶剂改性电解质染料敏化太阳能电池 的 Bode 图

Fig. 9 Bode plots of the DSSCs fabricated using electrolytes modified with different contents of DES 


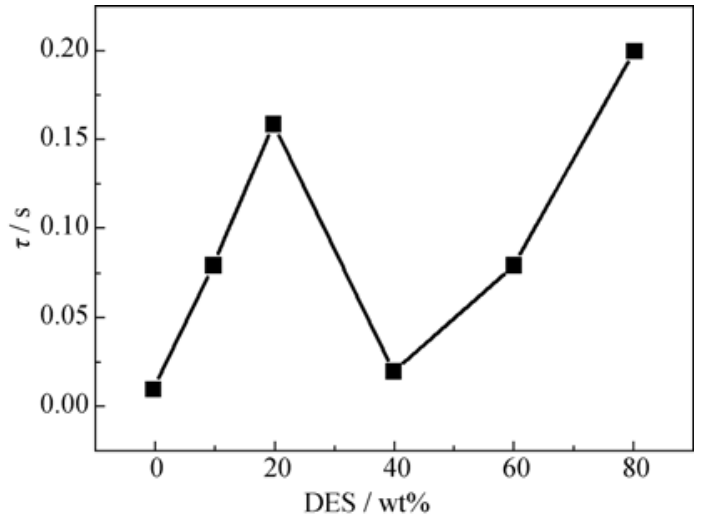

图 10 不同含量低共熔溶剂对光阳极中电荷电子寿命的影响 Fig.10 Influence of DES contents on electron lifetime in photoanode

电解质的界面能, 从而阻断了现有的导电通路 ${ }^{[28-29]}$, 使界面复合增加, 缩短电子寿命。继续增加低共熔 溶剂含量, 导电方式发生变化, 电解质逐渐呈现液 态电解质的性质，过量的 $\left(\mathrm{NH}_{2} \mathrm{CONH}_{2}\right)_{2}[\mathrm{Cl}]^{-}$发生离 解产生自由 $\mathrm{Cl}^{-}$与氢键给体 $\left(\mathrm{NH}_{2} \mathrm{CONH}_{2}\right)$, 破坏染料 分子之间氢键的交互作用，从而减少染料之间的团 聚, 增加电子浓度, 进而使电子寿命增加。电子寿命 的变化引起电子在 $\mathrm{TiO}_{2}$ 多孔薄膜中的存在量与电 子填充情况变化, 使 $\mathrm{TiO}_{2}$ 导带的准费米能级也随之 变化, 进而影响开路电压的变化 ${ }^{[36-37]}$ 。图 10 中电子 寿命的变化与表 1 中开路电压变化相一致。

\subsection{3 稳定性分析}

图 11 为 $40 \mathrm{wt} \%$ 低共熔溶剂改性电解质 DSSC 的 稳定性测试结果。结果显示, 经过 $270 \mathrm{~h}$ 的稳定性测 试, 40wt\%低共熔溶剂 DSSC 的短路电流密度 $\left(J_{\mathrm{sc}}\right)$ 衰 减至初始值的 $68 \%$, 开路电压 $\left(V_{\mathrm{oc}}\right)$ 衰减至初始值 的 $82 \%$, 光电效率 $(\eta)$ 衰减至初始值的 $64 \%$ 。造成光 电效率衰减可能是由于电解质中有机溶剂的蒸发,

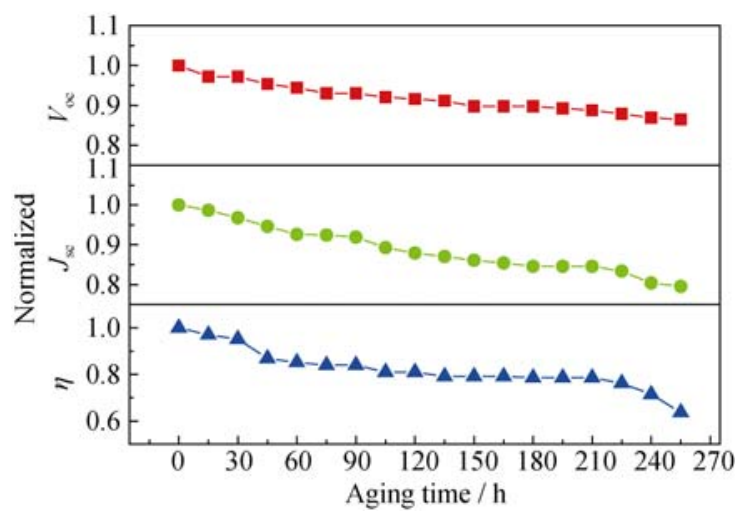

图 $1140 \mathrm{wt} \%$ 低共熔溶剂改性电解质染料敏化太阳能电池的 稳定性分析

Fig.11 Stablity test of $J_{\mathrm{sc},} V_{\mathrm{oc}}$, and $\eta$ for DSSC fabricated using $40 \mathrm{wt} \%$ EDS electrolyte
破坏了聚合物内部的网状结构, 影响了电解质内载 流子的扩散。结果还表明，低共熔溶剂对聚合物网 状结构的破坏作用较小，在提高器件光电效率的基 础上所制备光电器件仍具有较高的稳定性。

\section{3 结论}

实验考察了不同配比的低共熔溶剂添加剂对琼 脂糖基准固态电解质性能的影响，在确定低共熔溶 剂的最佳配比的基础上，优化电解质中低共熔溶剂 含量, 考察了其对琼脂糖基准固态电解质的电化学 性能的影响规律及相应 DSSC 光电性能的影响机 制。实验结果表明: 低共熔溶剂具有提高电解质 $\mathrm{I}_{3}-$ 浓度及离子电导率的作用，尿素/氯化胆碱为 $2: 1$ 的 低共熔溶剂电解质的染料敏化太阳能电池的各项性 能都要优于其他配比的低共熔溶剂电解质, 最佳离 子电导率为 $7.24 \mathrm{mS} / \mathrm{cm}$ 。考察了不同含量低共熔溶 剂对电解质中 $\mathrm{I}_{3}$-浓度及离子电导率的影响, 发现 $20 \mathrm{wt} \%$ 低共熔溶剂改性电解质的离子电导率达到最 大 $6.21 \mathrm{mS} / \mathrm{cm}$, 该电解质用于制备染料敏化太阳能 电池器件, 获得的 DSSC 最佳光电效率 $\eta=3.18 \%$, 短 路电流密度 $J_{\mathrm{sc}}=10.28 \mathrm{~mA} / \mathrm{cm}$, 开路电压 $V_{\mathrm{oc}}=0.59 \mathrm{~V}$, 填充因子 $F F=0.51$ 。

\section{参考文献:}

[1] 戴松元, 刘伟庆, 间金定. 染料敏化太阳能电池. 北京: 科学出 版社, 2014: 176-178.

[2] KOZYCZ L M, GAO D, SEFEROS D S. Compositional influence on the regioregularity and device parameters of a conjugated statistical copolymer. Macromolecules, 2013, 46(3): 613-621.

[3] COCILOVO B, AMOOALI A, LOPEZ-SANTLAAGO A, et al. Effect of modular diffraction gratings on absorption in P3HT: PCBM layers. Applied optics, 2013, 52(5): 1025-1034.

[4] NAZEERUDDIN M K, BARANOFF E, GRÄTZEL M. Dye-sensitized solar cells: a brief overview. Solar Energy, 2011, 85(6): 1172-1178.

[5] MATHEW S, YELLA A, GAO P, et al. Dye-sensitized solar cells with $13 \%$ efficiency achieved through the molecular engineering of porphyrin sensitizers. Nature Chemistry, 2014, 6(3): 242-247.

[6] WU J H, HAO S C, LAN Z, et al. A thermoplastic gel electrolyte for stable quasi - solid-state dye - sensitized solar cells. Advanced Functional Materials, 2007, 17(15): 2645-2652.

[7] BISQUERT J, CAHEN D, HODES G, et al. Physical chemical principles of photovoltaic conversion with nanoparticulate, mesoporous dye-sensitized solar cells. The Journal of Physical Chemistry B, 2004, 108(24): 8106-8118.

[8] KUBO W, KITAMURA T, HANABUSA K, et al. Quasi-solid-state dye-sensitized solar cells using room temperature molten salts and a low molecular weight gelator. Chemical Communications, 2002(4): 374-375.

[9] KUBO W, KAMBE S, NAKADE S, et al. Photocurrent-determining processes in quasi-solid-state dye-sensitized solar cells using ionic gel electrolytes. The Journal of Physical Chemistry B, 2003, 107(18): 4374-4381. 
[10] CAI N, ZHANG J, ZHOU D, et al. N-methyl-N-allylpyrrolidinium based ionic liquids for solvent-free dye-sensitized solar cells. The Journal of Physical Chemistry C, 2009, 113(10): 4215-4221.

[11] KUANG D, WANG P, ITO S, et al. Stable mesoscopic dye-sensitized solar cells based on tetracyanoborate ionic liquid electrolyte. Journal of the American Chemical Society, 2006, 128(24): 7732-7733.

[12] KUANG D, KLEIN C, ZHANG Z, et al. Stable, high - efficiency ionic - liquid - based mesoscopic dye - sensitized solar cells. Small, 2007, 3(12): 2094-2102.

[13] BAI Y, CAO Y, ZHANG HANG J, et al. High-performance dye-sensitized solar cells based on solvent-free electrolytes produced from eutectic melts. Nature materials, 2008, 7(8): 626-630.

[14] WANG P, WENGER B, HUMPHR-BAKER R, et al. Charge separation and efficient light energy conversion in sensitized mesoscopic solar cells based on binary ionic liquids. Journal of the American Chemical Society, 2005, 127(18): 6850-6856.

[15] LI D, WANG M, WU J, et al. Application of a new cyclic guanidinium ionic liquid on dye-sensitized solar cells (DSCs). Langmuir, 2009, 25(8): 4808-4814.

[16] MAZILLE F, FEI Z, KUANG D, et al. Influence of ionic liquids bearing functional groups in dye-sensitized solar cells. Inorganic chemistry, 2006, 45(4): 1585-1590.

[17] ABBOTT A P, CAPPER G, DAVIES D L, et al. Novel solvent properties of choline chloride/urea mixtures. Chemical Communications, 2003, 1: 70-71.

[18] ABBotT A P, BOOTHBy D, CAPPER G, et al. Deep eutectic solvents formed between choline chloride and carboxylic acids: versatile alternatives to ionic liquids. Journal of the American Chemical Society, 2004, 126(29): 9142-9147.

[19] ABBOTT A P, CULLIS P M, GIBSONI M J, et al. Extraction of glycerol from biodiesel into a eutectic based ionic liquid. Green Chemistry, 2007, 9(8): 868-872.

[20] JHONG H R, WONG D S H, WAN C C, et al. A novel deep eutectic solvent-based ionic liquid used as electrolyte for dye-sensitized solar cells. Electrochemistry Communications, 2009, 11(1): 209-211.

[21] RAMESH S, SHANTI R, MORRIS E. Studies on the plasticization efficiency of deep eutectic solvent in suppressing the crystallinity of corn starch based polymer electrolytes. Carbohydrate Polymers, 2012, 87(1): 701-706.

[22] KEBEDE Z, LINDQUIST S E. Donor-acceptor interaction between non-aqueous solvents and $\mathrm{I}_{2}$ to generate $\mathrm{I}_{3}{ }^{-}$and its implication in dye sensitized solar cells. Solar Energy Materials and Solar Cells, 1999, 57(3): 259-275.

[23] ABBOTT A P, HARRIS R C, RYDER K S. Application of hole theory to define ionic liquids by their transport properties. The Journal of Physical Chemistry B, 2007, 111(18): 4910-4913.
[24] SUN H, LI Y, WU X, et al. Theoretical study on the structures and properties of mixtures of urea and choline chloride. Journal of Molecular Modeling, 2013, 19(6): 2433-2441.

[25] ZHANG YING-YING, JI XIAO-YANG, LU XIAO-HUA. Properties and applications of choline chloride/urea and choline chloride/glycerol. SCIENTIA SINICA Chimica, 2014, 44(6): 927-941.

[26] ZHANG Q, VIGIER K D O, ROYER S, et al. Deep eutectic solvents: syntheses, properties and applications. Chemical Society Reviews, 2012, 41(21): 7108-7146.

[27] RAMESH S, LU S C. Effect of nanosized silica in poly (methyl methacrylate)-lithium bis (trifluoromethanesulfonyl) imide based polymer electrolytes. Journal of Power Sources, 2008, 185(2): 1439-1443.

[28] ANATHA P S, HARIHARAN K. Physical and ionic transport studies on poly (ethylene oxide)- $\mathrm{NaNO}_{3}$ polymer electrolyte system. Solid State Ionics, 2005, 176(1): 155-162.

[29] WINIE T, RAMESH S, AROF A K. Studies on the structure and transport properties of hexanoyl chitosan-based polymer electrolytes. Physica B: Condensed Matter, 2009, 404(21): 4308-4311.

[30] GORDON C M, MCLEAN A J. Photoelectron transfer from excited-state ruthenium (II) tris (bipyridyl) to methylviologen in an ionic liquid. Chemical Communications, 2000, 15: 1395-1396.

[31] SCHLICHTHÖRL G, HUANG S Y, SPRAGUE J, et al. Band edge movement and recombination kinetics in dye-sensitized nanocrystalline $\mathrm{TiO}_{2}$ solar cells: a study by intensity modulated photovoltage spectroscopy. The Journal of Physical Chemistry B, 1997, 101(41): 8141-8155.

[32] FUKE N, FUKUI A, KOMIYA R, et al. New approach to low-cost dye-sensitized solar cells with back contact electrodes. Chemistry of Materials, 2008, 20(15): 4974-4979.

[33] WANG M, LIN Y, ZHOU X, et al. Solidification of liquid electrolyte with imidazole polymers for quasi-solid-state dye-sensitized solar cells. Materials Chemistry and Physics, 2008, 107(1): 61-66.

[34] WANG W, GUO X, YANG Y. Lithium iodide effect on the electrochemical behavior of agarose based polymer electrolyte for dye-sensitized solar cell. Electrochimica Acta, 2011, 56(21): 7347 7351.

[35] KERN R, SASTRAWAN R, FERBER J, et al. Modeling and interpretation of electrical impedance spectra of dye solar cells operated under open-circuit conditions. Electrochimica Acta, 2002, 47(26): 4213-4225.

[36] HE J, BENKÖ G, KORODI F, et al. Modified phthalocyanines for efficient near-IR sensitization of nanostructured $\mathrm{TiO}_{2}$ electrode. Journal of the American Chemical Society, 2002, 124(17): 49224932.

[37] CHEN ANG-RAN, ZHAO WEI, CUI HOU-LEi, et al. $\mathrm{TiO}_{2}$ nanowires infiltrated with graphene-decorated mesoporous $\mathrm{TiO}_{2}$ for enhanced dye-sensitized solar cell. Journal of Inorganic Materials, 2015, 30(8): 891-896. 